\section{Transplante Simultâneo de Pâncreas e Rim: Uma Realidade em Nosso Meio}

$\mathrm{O}$

PACIENTE PORTADOR DE DIABETES mellitus do tipo 1 e com insuficiência renal crônica tem várias opções de tratamento, como permanecer em diálise, ser submetido a transplante de rim com doador vivo relacionado ou doador cadáver, receber um pâncreas após transplante renal ou ainda submeter-se ao transplante simultâneo de pâncreas e rim (SPR). Passaram-se quase 40 anos desde que Lillehei e equipe realizaram o primeiro transplante de pâncreas. Neste período de tempo as evoluções na técnica cirúrgica, na preservação de órgãos e nas drogas imunossupressoras levaram esta modalidade terapêutica a ser largamente utilizada em vários centros.

Atualmente mais de 17.000 transplantes já foram realizados e nosso país, felizmente, acompanhou essa evolução. Temos, segundo a ABTO Associação Brasileira de Transplantes de Órgãos, 18 centros cadastrados para a realização de transplante SPR e cinco para a realização de pâncreas isolado. No ano de 2002, estas equipes realizaram 143 SPR e 42 transplantes isolados de pâncreas, ou seja, 4,7\% dos transplantes de órgãos realizados naquele ano.

Neste número dos Arquivos, Nicoluzzi, Marmanillo e Repka (1) apresentam sua experiência em SPR, que é a modalidade mais utilizada em todos os centros transplantadores. Em relação à técnica utilizada para a drenagem do pâncreas exócrino, a escolha da entérica vem ganhando terreno sobre a drenagem vesical, com vantagens e desvantagens inerentes a cada uma è à experiência das equipes.

Nesta série inicial de pacientes os autores não encontraram rejeição pancreática aguda, o que, como descrito pelos mesmos, pode estar relacionado à imunossupressão agressiva realizada e ao pequeno tempo de seguimento.

Os resultados relacionados à sobrevida dos pacientes e dos enxertos vêm melhorando continuadamente na casuística brasileira, sendo que a morbidade permanece alta, em parte pela imunossupressão, mas também pela complexidade e pelo mau estado geral que nossos pacientes chegam, muitos deles após vários anos de diálise. Apesar de tudo, o transplante SPR é uma realidade inconteste em nosso meio, levando o paciente à normalização do controle glicêmico e, como vários trabalhos indicam, ao retardo ou até parada da evolução das complicações crônicas, notadamente a microangiopatia. Mais evidente ainda é a melhoria da qualidade de vida dos receptores e a maior sobrevida destes pacientes quando comparados aos que permanecem em tratamento diálitico.

Entretanto, não encontramos na literatura trabalhos que indubitavelmente comprovem qual é a melhor opção de tratamento para os portadores de diabetes mellitus tipo 1 com insuficiência renal crônica. A própria American Diabetes Association e a American Society of Transplantation recomendam que o transplante de pâncreas seja considerado para todo o paciente com diabetes tipo 1 que será transplantado ou planeje um transplante renal $(2,3)$. Entretanto, não fazem uma forte recomendação que

\section{editorial}

\author{
João Roberto de Sá
}


favoreça o SPR sobre o transplante de pâncreas após o de rim, que vem se tornando, ano a ano, cada vez mais freqüente e que pode ser uma excelente opção para o paciente que tenha a possibilidade de receber um rim de doador vivo relacionado.

Recentemente, Knoll e Nichol (4) publicaram um artigo sugerindo um modelo de decisão que auxilia na difícil tarefa de escolhermos qual a melhor terapia para o paciente, que leva em conta vários aspectos como os riscos de morbidade, mortalidade, fatores econômicos, e também a qualidade de vida dos pacientes. Trabalhos nesta linha, realizados em nosso meio, serão de grande valia no auxílio das decisões a serem tomadas.

\section{Referências}

1. Nicoluzzi JE, Marmanillo CW, Repka JCD. Transplante simultâneo de pâncreas-rim em portador de diabetes mellitus tipo 1 com insuficiência renal crônica. Experiência inicial do Hospital Angelina Caron. Arq Bras Endocrinol Metab 2003;47/3: -

2. American Diabetes Association. Pancreas transplantation for patients with type 1 diabetes. Diabetes Care 2003;26 (suppl. 1):S120

3. Kasiske BL, Cangro CB, Hariharan S, Hricik DE, Kerman R, Roth $D$, et al. The evaluation of renal transplant candidates: Clinical practice guidelines. Am J Transplant 2001;1:1-95

4. Knoll GA, Nichol G. Dialysis, kidney transplantation, or pancreas transplantation for patients with diabetes mellitus and renal failure: a decision analysis of treatment options. J Am Soc Nephrol 2003; 14:500-15.

\section{Endereço para correspondência:}

João Roberto de Sá

Disciplina de Endocrinologia, UNIFESP

Rua Pedro de Toledo, 910

04039-002 São Paulo, SP

e.mail: jrsa@uol.com.br 